\title{
MAGNITUDE, DURAÇÃO E ESPECIFICIDADE DA RESPOSTA SOROLÓGICA EM BOVINOS VACINADOS CONTRA O VÍRUS DA DIARRÉIA VIRAL BOVINA $(B V D V)^{1}$
}

\author{
MAGNITUDE DURATION AND SPECIFICITY OF THE SEROLOGICAL RESPONSE IN CATTLE \\ VACCINATED AGAINST BOVINE VIRAL DIARRHEA VIRUS (BVDV)
}

\author{
Fernanda Silveira Flores Vogel $^{2}$ Eduardo Furtado Flores $^{3}$ Rudi Weiblen $^{4}$ Sandra Vanderli Mayer $^{5}$ \\ Valter Leonardo de Quadros ${ }^{5}$ Ivomar Oldoni $^{5}$
}

RESUMO

A resposta sorológica induzida por três vacinas comerciais inativadas contra o vírus da Diarréia Viral Bovina $(B V D V)$ foi avaliada em bovinos imunizados três vezes (dias 0 , 30 e 180) e testados a diferentes intervalos após a vacinação. Trinta dias após a segunda vacinação, 74,5\% (70/94) dos animais apresentavam anticorpos neutralizantes contra o BVDV1 e 52,1\% (49/94) contra o BVDV-2. Os títulos médios (GMT) e o número de animais reagentes contra o BVDV-1 eram de 109,3(32/36); 54,6(22/28) e 25,5(16/30) para as vacinas $A, B$ e $C$, respectivamente; e de 19(27/36), 42,3(12/28) e 18,4(10/30) contra o $B V D V-2$. Os títulos reduziram-se aos 180 dias, sendo que 31,9\%(30/94) dos animais já não apresentavam atividade neutralizante frente ao BVDV-1 e 63,8\%(60/94) frente ao BVDV2. Nesta data, os títulos médios e o número de animais positivos frente ao BVDV-1 eram de 28,3 (30/36), 28,3(20/28) e 16,1(14/30) e frente ao BVDV-2 de 16,8(18/36), 21,6(10/28) e $28,3(6 / 30)$ para as vacinas $A, B$ e $C$, respectivamente. Após o reforço (dia 180), os títulos médios contra o BVDV-1 aumentaram significativamente nos três grupos vacinais e contra o BVDV-2 apenas no grupo A. Trinta dias após, os títulos médios e o número de reagentes contra o BVDV-1 eram de 104,8(23/24), $50,3(24 / 26)$ e 43,7(24/28) e contra o BVDV-2 de 33,4(23/24), 23,3(22/26) e 15,7(22/28) para as vacinas $A, B$ e $C$. Os títulos contra o BVDV-1 no dia 210 foram estatisticamente superiores aos títulos contra o BVDV-2 nos três grupos vacinais. $O$ soro de alguns animais positivos de cada grupo foi testado frente a quatro amostras brasileiras de BVDV-1 e duas de BVDV-2. Além dos títulos baixos a moderados, os testes de neutralização cruzada revelaram variações marcantes na atividade neutralizante frente a isolados de campo antigenicamente diferentes. Esses resultados demonstram que a vacinação não induziu uma resposta sorológica de magnitude e duração adequadas na maioria dos animais, principalmente frente à grande diversidade antigênica das amostras de BVDV.

Palavras-chave: vírus da Diarréia Viral Bovina, BVDV, vacinas, diversidade antigênica.

\section{SUMMARY}

The serological response induced by three inactivated commercial vaccines against bovine viral diarrhea virus $(B V D V)$ was evaluated in calves immunized three times (days 0, 30 and 180) and examined at different intervals after vaccination. Thirty days after the second vaccination, $74.5 \%$ (70/94) of the calves had developed neutralizing antibodies titers against BVDV-1 and $52.1 \%$ (49/94) against BVDV-2. The geometric mean titers (GMT) and the number of animals with antibodies to $B V D V-1$ were 109.3(32/36); 54.6(22/28) and 25.5(16/30) for vaccines $A, B$ e $C$, respectively and 19(27/36), 42.3(12/28) and 18.4(10/30) to BVDV-2. The antibody titers decreased by day 180, when 31.9\%(30/94) of the calves showed no neutralizing activity against BVDV-1 and 63.8\%(60/94) to $B V D V-2$. At that time, the GMTs and the number of animals seropositive to $B V D V-1$ were 28.3 (30/36), 28.3(20/28) and 16.1(14/30); and to BVDV-2 were 16.8(18/36), 21.6(10/28) and $28.3(6 / 30)$ for vaccines $A, B$ and $C$, respectively. After the third dosis (day 180), the antibody titers to BVDV-1 increased significantly in all groups whereas a significant increase in $B V D V-2$ titers was observed only for vaccine A. At day 210 , GMTs and the number of positive animals to $B V D V-1$ were 104.8(23/24), 50.3(24/26) and 43.7(24/28) and to BVDV-2 were $33.4(23 / 24), 23.3(22 / 26)$ and 15.7(22/28) for vaccines $A, B$ and $C$. The neutralizing activity against $B V D V-1$ was higher than to $B V D V-2$ in all groups at day 210. Sera from five seropositive animals of each vaccine group were tested against four Brazilian

\footnotetext{
${ }^{1}$ Parte da Dissertação de Mestrado do primeiro autor ao Programa de Pós-graduação em Medicina Veterinária (PPGMV), Universidade Federal de Santa Maria (UFSM). Trabalho realizado com suporte financeiro do CNPq, MCT, CAPES e Finep (PRONEX em Virologia Veterinária, 215-96).

${ }^{2}$ Médico Veterinário, aluno do PPGMV, UFSM. Professor substituto no Departamento de Microbiologia e Parasitologia (DMP), Centro de Ciências da Saúde, UFSM.

${ }^{3}$ Médico Veterinário, Mestre, PhD., Professor Adjunto do Departamento de Medicina Veterinária Preventiva (DMVP), Centro de Ciências Rurais (CCR) e do DMP, UFSM. Bolsista do CNPq (520758/96-0). 97105-900, Santa Maria, RS. Fone/fax: 55-220-8034. E-mail: flores@ccr.ufsm.br. Autor para correspondência.

${ }^{4}$ Médico Veterinário, Mestre, PhD., Professor Titular do DMVP e do DMP, UFSM. Bolsista do CNPq (520161/97-1).

${ }_{5}^{5}$ Acadêmico do Curso de Medicina Veterinária, UFSM. Bolsista de Iniciação Científica - CNPq/PIBIC/UFSM.
} 
$B V D V-1$ and two BVDV-2 isolates. In addition to the low and moderate titers, the cross-neutralization assays revealed a highly variable neutralizing activity against the Brazilian field isolates. These results demonstrated that the vaccination did not induce an adequate serological response in most animals, mainly due to the high antigenic variability of $B V D V$.

Key words: bovine viral diarrhea virus, BVDV, vaccines, antigenic diversity.

\section{INTRODUÇÃO}

O vírus da Diarréia Viral Bovina (BVDV) é um dos principais patógenos de bovinos. A infecção possui distribuição mundial e causa perdas significativas à pecuária bovina (BAKER, 1995). O BVDV é um vírus com envelope, que possui como genoma uma molécula de RNA de cadeia simples, polaridade positiva, com aproximadamente 12,5 quilobases. O BVDV pertence à família Flaviviridae, gênero Pestivirus, juntamente com o vírus da Doença da Fronteira de ovinos (BDV) e o vírus da Peste Suína Clássica (CSFV) (FRANCKI et al., 1991).

A infecção pelo BVDV pode resultar em uma variedade de manifestações que incluem infecções subclínicas, doença gastroentérica aguda ou crônica (Diarréia Viral Bovina, BVD), doença respiratória e BVD aguda e hemorrágica (BAKER, 1995). A infecção de fêmeas soronegativas com amostras não-citopáticas (ncp) geralmente resulta em transmissão transplacentária do vírus para o feto, podendo causar perdas embrionárias ou fetais, malformações, natimortalidade e o nascimento de terneiros fracos e inviáveis. A infecção de fêmeas entre os dias 40 e 120 de gestação pode resultar em imunotolerância fetal e no nascimento de animais persistentemente infectados (PI) (BROWNLIE, 1990; MOENNIG \& LIESS, 1995). Os animais PI eliminam o vírus em secreções e excreções e constituem-se na principal fonte de disseminação e perpetuação do vírus na população bovina (BRONWLIE, 1990).

Os isolados de campo do BVDV apresentam uma grande variabilidade antigênica, sendo que dois grupos genética e antigenicamente distintos já foram identificados, BVDV-1 e BVDV-2 (PELLERIN et al., 1994). Amostras de BVDV-2 são antigenicamente distintas das de BVDV-1, sobretudo na região da glicoproteína E2/gp53 (PELLERIN et al., 1994; VAN RIJN et al., 1997). A E2/gp53 é a principal glicoproteína do vírion e está envolvida na indução de anticorpos neutralizantes e proteção (DONIS, 1995). Por isso, a reatividade sorológica e proteção cruzada entre
BVDV-1 e BVDV-2 é geralmente muito baixa (PELLERIN et al., 1994; FLORES et al., 2000).

Após o reconhecimento da importância da infecção pelo BVDV para a pecuária bovina, vacinas atenuadas $e$ inativadas foram desenvolvidas e passaram a ser utilizadas para reduzir a gravidade da doença clínica e as perdas econômicas. No entanto, a grande variabilidade antigênica dos isolados de campo sempre representou um obstáculo para a obtenção de proteção cruzada contra o amplo espectro dos isolados (DUBOVI, 1992; VAN OIRSCHOT et al., 1999). O surgimento de amostras antigenicamente diferentes e altamente virulentas de BVDV no final da década de 80 (PELLERIN et al., 1994), denominadas de BVDV-2, reacendeu a discussão sobre a eficácia das vacinas (VAN OIRSCHOT et al., 1999; FULTON \& BURGE, 2000).

A infecção pelo BVDV está amplamente disseminada no rebanho bovino do Brasil (BOTTON et al., 1998; PITUCO \& DEL FAVA, 1998) e as amostras brasileiras de BVDV apresentam uma grande variabilidade antigênica (BOTTON $\boldsymbol{e t}$ al., 1998). Análise filogenética e antigênica de isolados brasileiros revelou a presença de vírus dos dois genótipos (BVDV-1 e BVDV-2) no rebanho brasileiro (FLORES $\boldsymbol{e t}$ al., 2000). Como a grande maioria das vacinas contra o BVDV, incluindo as comercializadas no país, contém apenas cepas de BVDV-1, é pertinente questionar-se sobre o grau de reatividade sorológica entre as cepas vacinais e as amostras de campo brasileiras.

Os objetivos desse experimento foram quantificar e determinar a duração e especificidade da resposta sorológica induzida em bovinos por três vacinas comerciais contra o BVDV.

\section{MATERIAL E MÉTODOS}

\section{Células e vírus}

A multiplicação e quantificação de vírus e testes de soroneutralização (SN) foram realizados com células MDBK (Madin Darby bovine kidney; American Type Culture Collection, CCL-22) livres de pestivírus. As células foram cultivadas em meio essencial mínimo (MEM), com penicilina ( $35 \mathrm{mg} / \ell$ ), estreptomicina $(200 \mathrm{mg} / \ell)$, suplementado com $5 \%$ de soro eqüino. As cepas padrão de BVDV-1 (Singer) e BVDV-2 (VS-253) foram cedidas pelo Dr Ruben Donis (University of Nebraska at Lincoln, Lincoln, NE, USA). As amostras de BVDV utilizadas nos testes de soro-neutralização cruzada (Tabela 1) foram isoladas no Brasil e caracterizadas anteriormente (BOTTON et al., 1998). 
Tabela 1 - Atividade neutralizante do soro de bovinos vacinados com três vacinas comerciais inativadas, frente a cepas padrão e amostras brasileiras de Virus da Diarréia Viral Bovina.

\begin{tabular}{|c|c|c|c|c|c|c|c|c|c|}
\hline \multirow[t]{3}{*}{ Vacina } & \multirow[t]{3}{*}{ Animal } & \multicolumn{2}{|c|}{ Cepas padrão } & \multicolumn{6}{|c|}{ Amostras brasileiras de BVDV-1 e BVDV- $2^{\mathrm{a}}$} \\
\hline & & \multirow{2}{*}{$\frac{\text { BVDV-1 }}{\text { Singer }}$} & \multirow{2}{*}{$\frac{\text { BVDV-2 }}{\text { VS-253 }}$} & \multicolumn{4}{|c|}{ BVDV-1 } & \multicolumn{2}{|c|}{ BVDV-2 } \\
\hline & & & & EMP-2 & SV126-1 & SV126-8 & UFSM-1 & VM-97 & SV-260 \\
\hline \multirow[t]{6}{*}{ A } & 1 & 320 & 80 & 160 & 320 & 160 & 20 & 160 & 10 \\
\hline & 2 & 80 & 320 & 160 & 320 & 80 & 10 & 160 & 160 \\
\hline & 3 & 80 & 40 & 40 & 320 & 80 & 20 & 40 & 10 \\
\hline & 4 & 80 & 20 & 160 & 160 & 40 & 10 & 10 & 10 \\
\hline & 5 & 80 & 40 & 160 & 80 & 20 & 10 & 10 & 40 \\
\hline & 6 & 40 & 80 & 80 & 40 & 80 & 10 & 5 & 40 \\
\hline \multirow[t]{6}{*}{ B } & 7 & 80 & 40 & 5 & $<5^{b}$ & $<5$ & 10 & $<5$ & $<5$ \\
\hline & 8 & 160 & 20 & 40 & 10 & 160 & 80 & 5 & 20 \\
\hline & 9 & 320 & 160 & 160 & 320 & 80 & 20 & 40 & 20 \\
\hline & 10 & 160 & 40 & 40 & 40 & 160 & 5 & 5 & 10 \\
\hline & 11 & 40 & 40 & 160 & 40 & 40 & 10 & 20 & 320 \\
\hline & 12 & 160 & 160 & 160 & 160 & 20 & 160 & 80 & 20 \\
\hline \multirow[t]{5}{*}{$\mathrm{C}$} & 13 & 80 & 40 & 40 & 40 & 20 & 10 & $<5$ & 10 \\
\hline & 14 & 10 & 10 & 40 & 40 & 80 & 10 & 5 & $<5$ \\
\hline & 15 & 20 & 160 & 80 & 40 & 40 & 20 & 10 & 10 \\
\hline & 16 & 40 & 10 & 20 & 5 & 5 & 10 & $<5$ & $<5$ \\
\hline & 17 & 80 & 40 & 20 & 5 & 10 & 10 & $<5$ & $<5$ \\
\hline
\end{tabular}

a Títulos de anticorpos neutralizantes expressos como a recíproca de maior diluição do soro capaz de prevenir a replicação do respectivo vírus $\left(100 \mathrm{TCID}_{50}\right)$.

${ }^{b}$ Soro negativo na menor diluição do soro utilizado no teste de SN (1:5).

\section{Animais, vacinas e protocolo de vacinação}

Foram utilizados 124 bovinos jovens (idade entre 8 e 24 meses), de raças de corte, soronegativos para o BVDV, provenientes de três propriedades localizadas na região central do Rio Grande do Sul. Os animais foram divididos aleatoriamente em quatro grupos. Três grupos foram vacinados $(A=36, B=28$ e $C=30)$ e dez animais de cada propriedade permaneceram como controles não-vacinados. Foram utilizadas três vacinas comerciais (vacinas A, B e C) que contêm cepas citopáticas e não citopáticas de BVDV inativadas, além de antígenos de outros patógenos bovinos. As vacinas $\mathrm{A}$ e $\mathrm{B}$ contêm hidróxido de alumínio como adjuvante, enquanto a vacina $\mathrm{C}$ contém adjuvante oleoso. Essas vacinas são indicadas para imunização de bovinos na dose de $5 \mathrm{~m} \ell$ por via intramuscular ou subcutânea. $O$ protocolo de vacinação foi o recomendado pelos fabricantes: primovacinação e revacinação 30 a 40 dias após. Aproximadamente 180 dias após a primovacinação, os animais receberam uma terceira dose da vacina. Alguns animais foram comercializados nesse intervalo e portanto não foram revacinados.

\section{Resposta sorológica}

Amostras de sangue para obtenção de soro foram coletadas no dia zero, 30, 60, 180 e 210.
As amostras de soro foram testadas para a presença de anticorpos neutralizantes contra o BVDV através de testes de soro-neutralização (SN). Os testes de SN foram realizados em paralelo, testando-se cada amostra de soro (quatro repetições) contra uma cepa de BVDV-1 (Singer) e de BVDV-2 (VS-253). Para avaliação da especificidade da resposta sorológica e do espectro de reatividade sorológica, o soro de alguns animais de cada grupo $(A=6 ; \quad B=6 ; \quad C=5)$ foi submetido a testes de SN cruzada frente a quatro isolados brasileiros de BVDV-1 e dois de BVDV-2 (Tabela 1). Os testes de SN foram realizados e interpretados de acordo com protocolo descrito anteriormente (BOTTON et al.,1998).

As médias dos títulos foram transformadas em títulos médios geométricos (GMT; THRUSFIELD, 1986) pela relação: GMT $=2^{\mathrm{a}}$, onde a é a média do título de anticorpos em cada vacina frente ao BVDV-1 e BVDV-2. Para esse cálculo, somente foram considerados os títulos de anticorpos dos animais soropositivos nos testes de $\mathrm{SN}$ (títulos $\geq$ 5). A análise estatística foi feita baseada no teste de Saphiro-Wilk (THRUSFIELD, 1986) com nível de significância de 5\%. Compararam-se os títulos médios entre vacinas em diferentes datas; títulos anti-BVDV-1 versus BVDV-2 nas três vacinas e títulos antes e depois do reforço.

\section{RESULTADOS}

Os resultados dos testes sorológicos realizados a diferentes intervalos após a vacinação estão resumidos na tabela 2. Nessa tabela, são apresentados os títulos médios (GMT) contra o BVDV-1 e BVDV-2 nas diferentes datas de coleta, o número de animais que reagiu sorologicamente e a relação entre os títulos contra o BVDV-1 versus BVDV-2. 
Tabela 2 - Resposta sorológica contra o vírus da Diarréia Viral Bovina (BVDV) induzida por três vacinas comerciais inativadas.

\begin{tabular}{|c|c|c|c|c|c|c|}
\hline \multirow{2}{*}{$\begin{array}{l}\text { Vacina } \\
\text { A }\end{array}$} & \multirow[t]{2}{*}{$\mathrm{Dpv}^{\mathrm{a}}$} & \multicolumn{2}{|c|}{ Soropositivos / total } & \multicolumn{2}{|c|}{ Anticorpos neutralizantes $(\mathrm{GMT})^{\mathrm{d}}$} & \multirow{2}{*}{$\begin{array}{c}\text { Relaçãa }^{\mathrm{e}} \\
\text { BVDV-1/BVDV-2 }\end{array}$} \\
\hline & & BVDV $-1^{\mathrm{b}}$ & BVDV $-2^{\mathrm{c}}$ & BVDV-1 & BVDV-2 & \\
\hline \multirow[t]{4}{*}{$\mathrm{n}=36^{\mathrm{g}}$} & 30 & $12 / 36(0-40)$ & $1 / 36(0-10)$ & 14,1 & 10 & 1,4 \\
\hline & 60 & $32 / 36(0-320)$ & $27 / 36(0-320)$ & 109,3 & 19,0 & 5,7 \\
\hline & 180 & $30 / 36(0-320)$ & $18 / 36(0-160)$ & 28,3 & 16,8 & 1,7 \\
\hline & 210 & $23 / 24(0-320)$ & $23 / 24(0-80)$ & 104,8 & 33,4 & 3,1 \\
\hline B & 30 & $9 / 28(0-320)$ & 5/28 (0-20) & 25,1 & 11,5 & 2,2 \\
\hline \multirow[t]{3}{*}{$\mathrm{n}=28$} & 60 & $22 / 28(0-320)$ & $12 / 28(0-320)$ & 54,6 & 42,3 & 1,3 \\
\hline & 180 & $20 / 28(0-80)$ & $10 / 28(0-80)$ & 28,3 & 21,6 & 1,3 \\
\hline & 210 & $24 / 26(0-320)$ & $22 / 26(0-160)$ & 50,3 & 23,3 & 2,2 \\
\hline $\mathrm{C}$ & 30 & $4 / 30(0-160)$ & 4/30 (0-10) & 40 & 10 & 4 \\
\hline \multirow[t]{3}{*}{$\mathrm{n}=30$} & 60 & $16 / 30(0-160)$ & $10 / 30(0-20)$ & 25,5 & 18,4 & 1,4 \\
\hline & 180 & $14 / 30(0-40)$ & $6 / 30(0-320)$ & 16,1 & 28,3 & 0,5 \\
\hline & 210 & $24 / 28(0-160)$ & $22 / 28(0-160)$ & 43,7 & 15,7 & 2,8 \\
\hline D & 210 & $0 / 30$ & $0 / 30$ & $<5^{\mathrm{f}}$ & $<5$ & - \\
\hline $\mathrm{n}=30$ & & & & & & \\
\hline
\end{tabular}

${ }^{a}$ Dia pós-vacinação: dia zero foi o dia da administração da primeira dose; dia 30, revacinação; dia 180, reforço.

${ }^{\mathrm{b}}$ Atividade neutralizante contra o BVDV-1, cepa Singer.

${ }^{c}$ Atividade neutralizante contra o BVDV-2, cepa VS-253.

${ }^{\mathrm{d}}$ Títulos médios geométricos frente aos respectivos vírus.

${ }^{\mathrm{e}}$ Relação entre os títulos de anticorpos neutralizantes frente ao BVDV-1 e frente ao BVDV-2.

${ }^{\mathrm{f}}$ Título menor do que 5 (menor diluição utilizada no teste de SN).

g "n" representa o número de animais por grupo no início do experimento. Alguns animais, dos três grupos vacinais, não receberam o reforço e, portanto, não foram testados aos 210 dias. superior às demais vacinas. Com relação ao BVDV-2, diferenças nos títulos entre vacinas somente foram observadas no dia 210, quando as vacinas A e B foram superiores à vacina C.

Em todos os grupos vacinais, a evolução dos títulos médios de anticorpos após a vacinação comportou-se de maneira semelhante (Figura 1). A única exceção foi a vacina $\mathrm{C}$, que apresentou redução nos títulos médios contra $\mathrm{O}$ BVDV-1 no dia 60. Isso foi devido ao grande número de animais com títulos baixos utilizados para o cálculo da média nessa data. Após o dia 60, os títulos médios reduziram-se progressivamente até o dia 180. Novamente, a vacina $C$ foi a exceção, pois os títulos médios anti-BVDV-2 aumentaram aos 180 dias. Esse aumento foi devido à exclusão do cálculo da média de vários animais que se tornaram negativos nessa data. Em contraste, os animais utilizados no cálculo da média possuíam títulos maiores. A revacinação induziu um aumento significativo dos títulos de anticorpos contra o BVDV-1 nos três grupos vacinais. Com relação ao BVDV-2, somente a vacina A induziu aumento significativo nos títulos.

Os resultados dos testes de especificidade da resposta sorológica estão apresentados na tabela 1. Para esses testes, foram selecionados alguns animais de cada grupo que apresentaram anticorpos contra o BVDV-1 (Singer) e BVDV-2 (VS-253). Em geral, a reatividade sorológica cruzada foi superior frente às amostras de BVDV-1. Diferenças nos títulos de até 32 vezes puderam ser observadas quando o soro de determinados animais foi testado frente a diferentes isolados. A reatividade sorológica foi bastante variável mesmo dentro do mesmo grupo (BVDV-1 x BVDV-1), com diferenças de até 32 vezes nos títulos neutralizantes. 


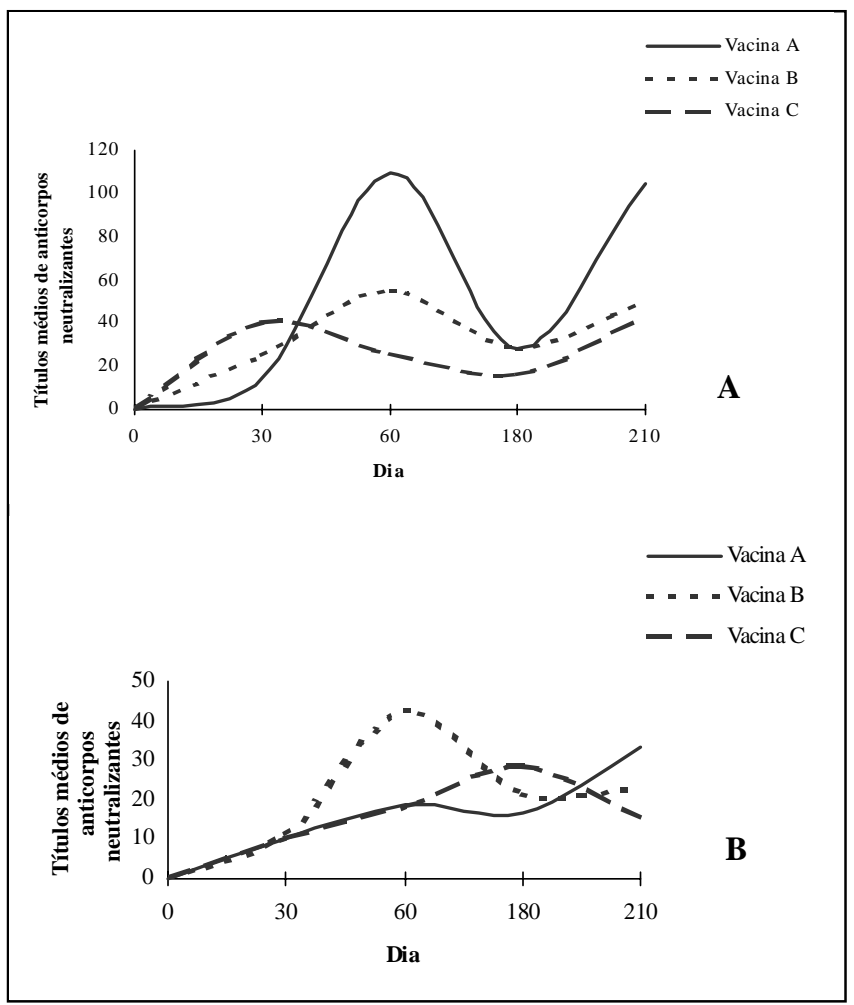

Figura 1 - Evolução dos títulos de anticorpos neutralizantes em bovinos imunizados com três vacinas comerciais contra o vírus da Diarréia Viral Bovina (BVDV). A. Títulos médios (GMT) de anticorpos neutralizantes frente ao BVDV-1 (Singer) e B. frente ao BVDV-2 (VS-253). As imunizações foram realizadas nos dias zero, 30 e 180 .

\section{DISCUSSÃO}

O objetivo do presente estudo foi avaliar a resposta sorológica induzida em bovinos por três vacinas inativadas contra o BVDV. O uso da vacinação para reduzir as perdas e controlar a infecção pelo BVDV tem aumentado consideravelmente no Brasil nos últimos anos e a tendência é de que essa prática torne-se cada vez mais difundida. No entanto, as estratégias e indicações para a imunização, assim como o perfil das vacinas utilizadas, não têm sido suficientemente discutidos. Além disso, as características das vacinais atuais e a sua eficácia frente ao recente surgimento do BVDV-2 e contra a grande diversidade antigênica dos isolados de campo merecem análise criteriosa.

Os testes sorológicos realizados a diferentes intervalos após a vacinação demonstraram que as vacinas utilizadas, com algumas diferenças entre os grupos, induziram níveis baixos a moderados de anticorpos na maioria dos animais. A magnitude da resposta foi estatisticamente inferior frente ao BVDV-2 nos três grupos vacinais. Além disso, uma parcela dos animais não apresentou anticorpos contra o BVDV-1, e principalmente contra o BVDV-2, sobretudo aos 180 dias. Resultados semelhantes têm sido relatados em outros testes vacinais, sendo que títulos baixos e de curta duração de anticorpos são mais freqüentemente observados com o uso de vacinas inativadas (BOLIN, 1995; FULTON et al., 1995; FULTON \& BURGE, 2000). A curta duração dos níveis de anticorpos induzidos por vacinas inativadas indica a necessidade de revacinações a intervalos inferiores a um ano, como tem sido recomendado para algumas vacinas (BOLIN, 1995). Títulos de anticorpos mais elevados e de maior duração podem ser obtidos com o uso de vacinas com vírus vivo modificado (BOLIN, 1995; VAN OIRSCHOT $\boldsymbol{e} t$ $\boldsymbol{a l} .$, 1999). Os títulos mais baixos de anticorpos contra o BVDV-2 observados refletem a formulação da maioria das vacinas atuais, que contém apenas cepas de BVDV-1. Vacinas contendo vírus dos dois genótipos têm sido recentemente desenvolvidas e utilizadas na América do Norte (FULTON \& BURGE, 2000; CORTESE, 2000), mas ainda não foram licenciadas no Brasil.

No presente estudo, a revacinação aos 180 dias induziu uma resposta secundária que resultou em aumento dos títulos de anticorpos contra o BVDV-1 na maioria dos animais dos três grupos. Aos 210 dias, 95,9\% (71/74) dos animais apresentavam atividade neutralizante frente ao BVDV-1, em títulos moderados (vacina $A=104,8$; vacina $B=50,3$ e vacina $C=43,7$ ) mas superiores aos observados aos 180 dias. No entanto, alguns animais (sobretudo aqueles com títulos de 80 e 160) não responderam à revacinação, e alguns títulos mantiveram-se nos níveis anteriores. Isso foi devido possivelmente à interferência dos anticorpos vacinais pré-existentes, como têm sido demonstrado para anticorpos colostrais e vacinais. Essa interferência é mais acentuada quando se utiliza vacinas inativadas, mas também ocorre com o uso de vacinas atenuadas (BOLIN, 1995; FULTON $\boldsymbol{e t}$ al., 1995; FULTON \& BURGE, 2000).

Os níveis de anticorpos neutralizantes correlacionados com proteção contra o BVDV ainda não foram determinados. No entanto, títulos de 80 têm sido sugeridos como parâmetro-base para avaliar-se proteção clínica entre amostras de BVDV antigenicamente semelhantes (DUBOVI, E. comunicação pessoal). Em experimentos recentes de proteção vacinal, títulos $\geq 240$ foram capazes de proteger contra a infecção respiratória enquanto 
títulos $\leq 60$ não conferiram proteção (FULTON \& BURGE, 2000). No presente estudo, apenas 11,7\% (11/94) dos animais apresentaram títulos superiores a 80 contra o BVDV-1 aos 180 dias. Esses valores foram ainda menores em relação ao BVDV-2: aos 180 dias, apenas 6,4\% (6/94) dos animais possuíam títulos superiores a 80. Aos 210 dias, 43,7\% (28/64) dos testes de neutralização cruzada resultaram em títulos $\geq 80$ frente às amostras brasileiras de BVDV1 e 5 de $34(14,7 \%)$ frente às amostras brasileiras de BVDV-2. Esses resultados demonstram que, mesmo nos testes realizados poucos dias após o reforço, uma parcela significativa dos animais dos três grupos vacinais não respondeu à vacinação em títulos adequados, principalmente contra o BVDV-2. Animais com títulos neutralizantes inferiores a 80 provavelmente estariam desprotegidos frente à infecção com vírus de campo.

A marcante diversidade antigênica entre os isolados de campo do BVDV constitui-se no maior obstáculo para a obtenção de resposta imunológica de amplo espectro através de vacinação (DUBOVI, 1992; BOLIN, 1995). Amostras de BVDV-1 e BVDV-2 são muito diferentes entre si, sobretudo na glicoproteína E2/gp53 (VAN RIJN et $\boldsymbol{a l} .$, 1997). Por isso, a atividade neutralizante cruzada entre BVDV-1 e BVDV-2 é geralmente muito baixa (PELLERIN et al., 1994; FLORES et al., 2000). Estudos de neutralização cruzada 'in vitro' têm reafirmado essa diversidade antigênica e alertado para as suas possíveis implicações para o diagnóstico e proteção vacinal (EDWARDS \& PATON, 1995; VAN OIRSCHOT $\boldsymbol{e}$ t al., 1999). Nos testes de SN cruzada com amostras brasileiras, diferenças de até 32 vezes nos títulos foram observadas quando algumas amostras de soro foram testadas frente a isolados de BVDV-1 e BVDV-2. Estudos anteriores demonstraram que títulos neutralizantes de 3200 contra uma determinada amostra podem falhar em neutralizar amostras antigenicamente diferentes em diluições de 1:10 (BOTTON et al., 1998). Curiosamente, os títulos neutralizantes frente à amostra UFSM-1 (caracterizada como BVDV-1) foram muito diferentes dos títulos contra amostras de BVDV-1. Esses resultados demonstram que além das diferenças entre os genótipos 1 e 2 , diferenças antigênicas marcantes ocorrem também dentro de um mesmo genótipo. A grande variação nos títulos séricos frente a diferentes isolados dificulta a obtenção de resposta sorológica uniforme e inviabiliza o estabelecimento definitivo dos títulos de anticorpos que estariam correlacionados com proteção.
Os efeitos da diversidade antigênica poderiam ser minimizados pela formulação de vacinas contendo vírus dos dois genótipos. Vacinas contendo cepas de BVDV-1 e BVDV-2 começaram recentemente a ser produzidas e comercializadas na América do Norte (FULTON \& BURGE, 2000; CORTESE, 2000). A formulação de vacinas com amostras de vírus representativas das amostras circulantes na população poderia ser outra alternativa (EDWARDS \& PATON, 1995; FLORES et al., 2000). Revacinações com vacinas contendo vírus heterólogos aos da primovacinação também têm sido sugeridas como forma de aumentar o espectro de proteção (FULTON et al., 1995). Um espectro mais amplo de proteção também pode ser obtido com o uso vacinas atenuadas, provavelmente pela resposta imunológica contra epitopos conservados nas proteínas não-estruturais do vírus.

Os conceitos sobre proteção vacinal contra o BVDV vêm se modificando desde o seu reconhecimento como patógeno de bovinos há mais de meio século (OLAFSON et al., 1946). Com a elucidação do mecanismo da geração de animais PI e da sua importância na epidemiologia da infecção (BROWNLIE, 1990), passou a considerar-se que as vacinas deveriam sobretudo conferir proteção fetal (DUBOVI, 1992). No entanto, após o surgimento das cepas altamente virulentas de BVDV-2, a necessidade de proteção contra a doença clínica voltou a ganhar ênfase (VAN OIRSCHOT $\boldsymbol{e t}$ al., 1999). A obtenção de proteção fetal pela vacinação tem sido mais problemática do que a obtenção de proteção clínica. Em geral, tem sido demonstrado que a proteção fetal conferida pela vacinação é freqüentemente incompleta (VAN OIRSCHOT $\boldsymbol{e t}$ al., 1999).

Em resumo, as observações mais relevantes do presente experimento foram: 1. As vacinas induziram títulos baixos a moderados na maioria dos animais, sobretudo contra o BVDV-2; 2. Vários animais não responderam sorologicamente à vacinação; 3. Os títulos de anticorpos induzidos pelas vacinas variaram amplamente entre os animais; 4. A atividade neutralizante do soro dos animais vacinados foi muito variável frente a amostras de campo brasileiras; 5. A resposta sorológica induzida pela vacinação foi de curta duração na maioria dos animais. Essas observações pretendem contribuir para uma discussão mais consistente sobre as estratégias de formulação, licenciamento e utilização de vacinas, sobretudo frente ao uso crescente da vacinação como meio de combate à infecção e enfermidades causadas pelo BVDV no país. 


\section{AGRADECIMENTOS}

Ao setor de bovinocultura de corte da UFSM, na pessoa do professor João Restle, pela cedência de parte dos animais utilizados no experimento. Aos estudantes do setor de bovinocultura de corte e do laboratório de virologia da UFSM, pelo auxilio nas atividades com os animais.

\section{COMUNICAÇÃO PESSOAL}

DUBOVI, E.J. EJ5@ cornell.vet.com Cornell University, Ithaca, NY. College of Veterinary Medicine; Diagnostic Laboratory.

\section{REFERÊNCIAS BIBLIOGRÁFICAS}

BAKER, J.C. Clinical manifestations of bovine viral diarrhea infection. Vet Clin North Amer: Food Animal Practice, v.11, p.425-445, 1995.

BOLIN, S.R. Control of bovine viral diarrhea infection by use of vaccination. Vet Clin North Amer: Food Animal Practice, v.11, p.615-625, 1995 .

BOTTON, S.A.; SILVA, A.M.; BRUM, M.C.S., et al. Antigenic characterization of Brazilian isolates of bovine viral diarrhea virus (BVDV) with monoclonal antibodies and by crossneutralization. Braz J Med Biol Res, v.31, p.1429 1438,1998 .

BROWNLIE, J. The pathogenesis of bovine viral diarrhea virus infections. Rev Sci Tech, v.9, p.43-59, 1990.

CORTESE, V. Type 2, too! Bovi-Shield now with proven protection against type 1 and type 2 BVD. Topics in Veterinary Medicine, v.10, p.14-20, 2000.

DONIS, R.O. Molecular biology of bovine viral diarrhea virus and its interactions with the host. Vet Clin North Amer: Food Animal Practice, v.11, n.3, p.393-423, 1995.

DUBOVI, E.J. Genetic diversity and B VD virus. Comp Immun Microbiol Dis, v.15, p.155-162, 1992.

EDWARDS, S.; PATON, D. Antigenic diferences among pestiviruses. Vet Clin North Amer: Food Animal Practice, v.11, p.563-577, 1995.
FLORES, E.F.; GIL, L.H.V.G.; BOTTON, S.A., et al. Clinical, pathological and antigenic aspects of bovine viral diarrhoea virus (BVDV) type 2 isolates identified in Brazil. Vet Microbiol, v.77, p.175-183, 2000 .

FRANCKI, R.; FAUQUET, C.; KNUDSON, D., et al. Classification and nomenclature of viruses. Wien-New York: Springer-Verlag. Fifth Report of the International Committee on Taxonomy of Viruses (ICTV). Arch Virol [Suppl.2], v.2, p.223-427, 1991.

FULTON, R.W.; CONFER, A.W.; BURGE, L., et al. Antibody responses by cattle after vaccination with commercial viral vaccines containing bovine hespesvirus-1, bovine viral diarrhea virus, parainfluenza-3 virus, and bovine respiratory syncytial virus immunogens and subsequent revaccination at day 140. Vaccine, v.13, n.8, p.725-733, 1995.

FULTON, R.W.; BURGE, L.J. Bovine viral diarrhea types 1 and 2 antibody response in calves receiving modified live virus or inactived vaccines. Vaccine, v.19, p.264-274, 2000.

MOENNIG, V.; LIESS, B. Pathogenesis of intrauterine infections with bovine viral diarrhea virus. Vet Clin North Amer: Food Animal Practice, v.11, p.477-487, 1995.

OLAFSON, P.; MacCULLUM, A.D.; FOX, F.H., et al. An apparently new transmissible disease of cattle. Cornell Vet, v.36, p.205-213, 1946.

PELLERIN, C.; VAN DEN HURK, J.; LECOMTE, J. Identification of a new group of bovine viral diarrhea virus strains associated with severe outbreaks and high mortalities. Virology, v.203, p.260-267, 1994

PITUCO, E.M.; DEL FAVA, C. Situação do BVDV na América do Sul. In: SIMPÓSIO INTERNACIONAL HERPESVÍRUS BOVINO \& VÍRUS DA DIARRÉIA VIRAL BOVINA. Santa Maria, RS. Anais ... Santa Maria : Pallotti, 1998. p.49.

THRUSFIELD, M. Veterinary epidemiology. London : Butterworth, 1986. 280p. Cap.16: Serological epidemiology: p.175-185.

VAN OIRSCHOT, J.T.; BRUSCHKE, C.J.M.; Van RIJN, P.A Vaccination of cattle against bovine viral diarrhoea. Vet Microbiol, v.64, p.169-183, 1999.

VAN RIJN, P.A.; VAN GENNIP, H.G.P.; LEENDERTSE, C.H., et al. Subdivision of the pestivirus genus based on envelope glycoprotein E2. Virology, v.231, p.337-348, 1997. 